\title{
Comparison of determination methods of vibration's damping coefficients for complex structures
}

\author{
Andrzej Flaga ${ }^{1,2}$, Jacek Szulej ${ }^{1}$, Piotr Wielgos ${ }^{1}$ \\ ${ }^{1}$ Department of Structural Mechanics, Faculty of Civil and Sanitary Engineering, \\ Lublin University of Technology, 20-618 Lublin, Nadbystrzycka 40, e-mail: p.wielgos@pollub.pl \\ ${ }^{2}$ Wind Engineering Laboratory, Faculty of Civil Engineering, Cracow University of Technology, \\ 31-864 Cracow, Jana Pawta II 37/3a
}

\begin{abstract}
The purpose of this paper is to present methods of vibrations damping coefficient determination. The methods, such as collocation method, two energetic methods and half-power bandwidth method concern composite structures. The verification of methods has been taken into account in this work. Two real compound models and two numerical models have been created. Time series of vibrations of these models have been measured and calculated. The comparison of four methods has been made on the basis of obtained results.
\end{abstract}

Key words: damping, potential energy method, kinetic energy method, collocation method, half-power bandwidth method.

\section{Introduction}

While designing bridges, footbridges and viaducts - these are structures having greater spans and at the same time being less stiff - it is important to determine the dynamic response of structure in the correct way. One of the main parameters describing behaviour of such a structure is damping coefficient of vibrations.

Several methods of determining the damping level are well known, for instance:

- energetic methods [8], in which it is possible to determine damping coefficient on the basis of defining changes in vibration of potential or kinetic energy;

- half-power bandwidth method [9], in which it is possible to determine damping coefficient on the basis of spectral processing of time series of vibration;

- collocation method [4], in which damping coefficients are achieved by using spectrum analyses of vibration.

While determining damping coefficients of a structure vibration it is necessary to remember its complexity (multi-material structures) as well as the type of work of its particular structural elements.

The aim of the work is to present and assess methods of damping determination in structures. The verification of the methods is performed on the basis of theoretical structure calculations consisting of three materials as well as on research carried out 
on two two-material composite structure models. Time series of displacements are achieved by two methods: by test and using mechanical transmittance.

\section{Application of mechanical transmittance to determine the structure response}

The elementary motion equation $n$-degree-of-freedom ( $n$-DOF) linear timeinvariant system can be written in a matrix form as:

$$
\mathbf{M} \ddot{\mathbf{y}}+\mathbf{C} \dot{\mathbf{y}}+\mathbf{K y}=\mathbf{p},
$$

where: $\mathbf{M}, \mathbf{C}$, and $\mathbf{K}$ are $n x n$ mass, damping and stiffness matrices; $\mathbf{y}$ and $\mathbf{p}$ are $n x 1$ displacement and force vectors.

Solution of the system defined by equation (1) can be expressed as:

$$
\mathbf{y}(t)=\int_{0}^{\infty} \mathbf{h}(\tau) \mathbf{p}(t-\tau) d \tau,
$$

where $\mathbf{h}(\tau)$ is impulse response vector; $\mathbf{p}$ is force vector expressed as $\mathbf{p}=\left[0,0 \ldots 0, \delta_{k}(\tau), 0 \ldots 0\right]^{T}$ where $\delta_{k}(\tau)$ is the Dirac delta.

Mechanical transmittance is a matrix $\mathbf{H}(f)$ whose elementary element $H_{i k}(f)$ is Fourier transform of impulse response $h_{i k}(\tau)$ :

$$
H_{i k}(f)=\int_{0}^{\infty} h_{i k}(\tau) e^{-j 2 \pi f \tau} d \tau,
$$

where $H_{i k}=\left[H_{1 k}, \ldots H_{i k}, \ldots H_{n k}\right]^{T}$; the impulse response $h_{i k}(\underline{\tau})$ is $i$-th response of a $k$-th excitation by single impulse function applied on starting time $\tau=0$.

Using Fourier transformation of equation of motion (1) results in:

$$
\left(\mathbf{K}-4 \pi^{2} f^{2} \mathbf{M}+j 2 \pi f \mathbf{C}\right) \mathbf{H}_{k}=\mathbf{1}_{k} .
$$

$H_{i k}$ is complex number in general and can be defined as:

$$
\begin{aligned}
& H_{i k}=\left|H_{i k}\right| e^{j \Theta_{i k}}=\operatorname{Re} H_{i k}+j \operatorname{Im} H_{i k}, \\
& \left|H_{i k}\right|=\sqrt{\left(\operatorname{Re} H_{i k}\right)^{2}+\left(\operatorname{Im} H_{i k}\right)^{2}} ; \arg H_{i k}=\Theta_{i k}=\operatorname{arctg} \frac{\operatorname{Re} H_{i k}}{\operatorname{Im} H_{i k}},
\end{aligned}
$$

where : $\left|H_{i k}\right|, \Theta_{i k}$ are modulus and argument of $H_{i k}$.

Using equations (6) the equation (7) is obtained:

$\operatorname{Re} \mathbf{G} \operatorname{Re} \mathbf{H}_{k}-\operatorname{Im} \mathbf{G} \operatorname{Im} \mathbf{H}_{k}+j\left[\operatorname{Im} \mathbf{G} \operatorname{Re} \mathbf{H}_{k}+\operatorname{Re} \mathbf{G} \operatorname{Im} \mathbf{H}_{k}\right]=\mathbf{1}_{k}$.

The realization of single impulse excitation for all DOFs in sequence results in full matrix of mechanical transmittance $\mathbf{H}(f)$ :

$$
\begin{aligned}
& \operatorname{Re} \mathbf{H}_{k}=\left\{\operatorname{Re} \mathbf{G}+\operatorname{Im} \mathbf{G}[\operatorname{Re} \mathbf{G}]^{-1} \operatorname{Im} \mathbf{G}\right\}^{-1} \mathbf{1}_{k} \\
& \operatorname{Im} \mathbf{H}_{k}=[\operatorname{Re} \mathbf{G}]^{-1} \operatorname{Im} \mathbf{G} \operatorname{Re} \mathbf{H}_{k}
\end{aligned}
$$


Using Fourier transform on equation (2) results in:

$$
\mathbf{Y}(f)=\mathbf{H}(f) \mathbf{P}(f)=\boldsymbol{F}[\mathbf{y}(t)],
$$

where: $\mathbf{Y}(f), \mathbf{P}(f)$ are Fourier transform of structure response and applied excitation. $\mathbf{H}(f)$ is mechanical transmittance $[\mathrm{m} / \mathrm{N}])$.

Knowing matrix of transmittance $\mathbf{H}(f)$ and Fourier transform $\mathbf{P}(f)$, structure response can be defined in a simple way through determination of inverse Fourier transform[2]:

$$
y(t)=\boldsymbol{F}^{-1}[\mathbf{Y}(f)]=\boldsymbol{F}^{-1} \mathbf{H}(f) \mathbf{P}(f) .
$$

\section{Description of methods used to determine damping level}

\subsection{Method based on potential energy calculations of vibrating structure}

The method of the damping level determination based on potential energy was described by Yamaguchi and Ito [8], for structure consisting of different structural parts (eg. platforms, pillars and hangers in bridges). Logarithmic decrement of damping $\delta_{i}$ is defined for $i$-th mode, just like for single DOF, according to the equation:

$$
\delta_{i}=\frac{D_{i}}{4 \pi U_{i}},
$$

where $D_{i}$ denotes dissipated energy per cycle of the $i$-th mode, $U_{i}$ is potential energy per one cycle of the $i$-th mode.

For structure consisting of different structural parts at different dissipated energy values, dissipated energy and total potential energy can be written as:

$$
D_{i}=\sum_{j=1}^{n} D_{i j} ; U_{i}=\sum_{j=1}^{n} U_{i j},
$$

where $D_{i j}$ denotes dissipated energy share of the $j$-th material in structure with reference to $i$-th mode shape; $U_{i j}$ - potential energy part of the $j$-th material in structure with reference to $i$-th mode.

Potential energy $U_{i j}$ is a sum of strain energy $V_{i j}$ at small deformation domain and energy $U_{i j}{ }^{0}$ coming from initial stress or large deformation (non-linear mechanic domain):

$$
U_{i j}=V_{i j}+U_{i j}^{0} \text {. }
$$

Dissipated energy per cycle for single material can be expressed as:

$$
D_{i j}=2 \pi \psi_{j} V_{i j}
$$

where $\psi_{j}$ is coefficient of absorption (specific damping) for given material.

Finally, logarithmic decrement of damping value with reference to $i$-th mode of vibration, taking equation (11-14) into account results in: 


$$
\delta_{i}=\frac{1}{2} \sum_{j=1}^{n} \psi_{j} \frac{V_{i j}}{U_{i}} .
$$

Strain energy $V_{i j}$ is determined from equation:

$$
V_{i j}=\frac{1}{2} \boldsymbol{\varphi}_{i}^{T} \mathbf{K}_{j} \boldsymbol{\varphi}_{i},
$$

where $\varphi_{i}$ denotes normalized eigenvector of the $i$-th mode; $\mathbf{K}_{j}$ is stiffness matrix of the $j$-th material in structure.

\subsection{Method based on the kinetic energy calculations of vibrating structure}

Owing to the basic assumptions of energetic method, depicted in p. 3.1. damping value was determined, on the basis of kinetic energy structure [4]. This method allows to determine damping more precisely than other with use of methods based on potential energy, because various layers are taken into account, whose stiffness is usually omitted. The layers have considerable kinetic energy and damping properties (eg. asphalt concrete in the surface of a viaduct, finishing materials).

The difference of defining the damping coefficient is based on including maximum of kinetic energy $E_{i j}$, instead of maximum of potential energy, described by formula (17). Kinetic energy can be expressed by the following formula:

$$
E_{i j}=\frac{1}{2} \mathbf{V}_{i}^{T} \mathbf{M}_{j} \mathbf{V}_{i},
$$

where $\mathbf{M}_{j}$ are inertial matrices of the $j$ th material in structure, $\mathbf{V}_{i}=\varphi_{i} \omega_{i}$ is maximum vibration velocity vector of the $i$-th mode, $\omega_{i}$ is natural circular frequency of the $i$-th mode.

Kinetic energy can be expressed as:

$$
E_{i j}=\frac{1}{2} \boldsymbol{\varphi}_{i}^{T} \mathbf{M}_{j} \boldsymbol{\varphi}_{i} \omega_{i}^{2} .
$$

Finally, logarithmic damping decrement value with reference to $i$-th mode of vibration, taking into account equation (12-15) results in:

$$
\delta_{i}=\frac{1}{2} \sum_{j=1}^{n} \psi_{j} \frac{E_{i j}}{U_{i}} .
$$

\subsection{Collocation method}

Collocation method [3] is based on the spectrum analysis of time series of free vibrations of investigated structures and consists in identification of parameters of special approximate function. If used, the function allows for precise calculation of damping level (damping coefficient $\beta$ ).

The order of activities while defining damping of the examined construction:

- Accelerations in free vibration of structure are measured (using sensors accel- 
erometers) and on the basis of these measurements it is possible to achieve time processes $f(t)$.

- Carrying out spectral analysis of time processes $f(t)$ with the use of FFT (fast Fourier transform); as a result the function $F=F F T\{f(t)\}$ is determined and natural circular frequency $\omega_{i}$, corresponding to local extremes FFT.

- It is assumed that vibrations of examined structure are the sum of harmonic damped vibrations of different frequency (damping is described by substitute viscous model), as in the following equations:

$$
y(t)=\sum_{i}\left\{A_{i} e^{-\beta_{i} t} \sin \left(\omega_{i}^{*} t\right)+B_{i} e^{-\beta_{i} t} \cos \left(\omega_{i}^{*} t\right)\right\} ;\left(\omega_{i}^{*}\right)^{2}=\left(\omega_{i}\right)^{2}-\left(\beta_{i}\right)^{2},
$$

where: $\omega_{i}$, is $i$-th natural circular frequency for undamped system; $A_{i}, B_{i}$ are amplitudes of natural vibrations, $\beta_{i}$ is damping parameter with reference to $i$-th circular frequency.

- Approximation of function $F^{2}$ by function $Y^{2}$, where $Y$ is defined by:

$$
Y=F F T\{y(t)\}=\int_{-\infty}^{\infty} y(t) \frac{1}{\sqrt{2 \pi}} e^{-i s t} d t .
$$

\subsection{Half-power bandwidth method}

The method was described in [9]. Damping coefficient of the $i$-th mode is achieved by using spectrum analysis of time processes of vibration. It is based on interpreting three values of frequency, of which there are three characteristic points corresponding to extreme of function and points lying at the height of $\sqrt{2} / 2$ extreme. On the basis of interpreted frequency, logarithmic decrement of damping is calculated by:

$$
\delta_{i}=\pi\left(\frac{\omega_{2}-\omega_{1}}{\omega}\right)
$$

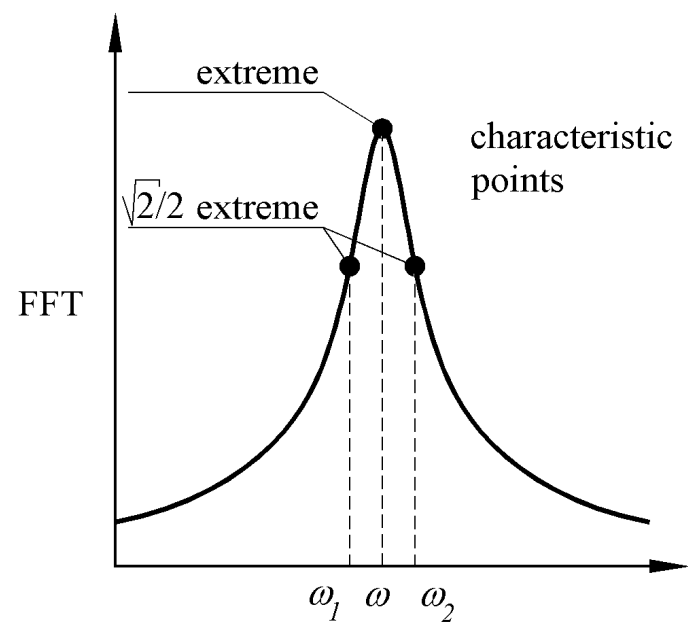

Fig. 1. Reading out method of values on half power bandwidth method. 


\section{Comparison of methods determination damping coefficients}

\subsection{Analytical example - theoretical three-materials cantilever model}

The cantilever model (height $80 \mathrm{~m}$ ), consisting of three different materials and whose scheme is depicted in the Fig. 2, has been taken into consideration. The damping matrix of the main structure $\mathbf{C}$ has been bold in the indirect way, using the mass-stiffness damping model (Reyleigh's model). It has been assumed that the same damping values of particular materials was identical for the first two natural frequencies of a structure. Values of damping coefficients are determined according to literature $[5,6,7]$ (reinforced concrete $\delta_{\dot{z}}=0,15$, steel $\delta_{s}=0,05$, wood $\delta_{d}=0,1$ ).

Impulse load has been applied to the model at subsegment discrete points along the height of the model. By the fully determined transmittance matrix of the structure (Fig. 4) and Fourier transform of excitation, the responses of each points of the structure have been determined (Fig. 3). Damping coefficients of the analyzed structure are compared in the Tab. 1 and Tab. 2.
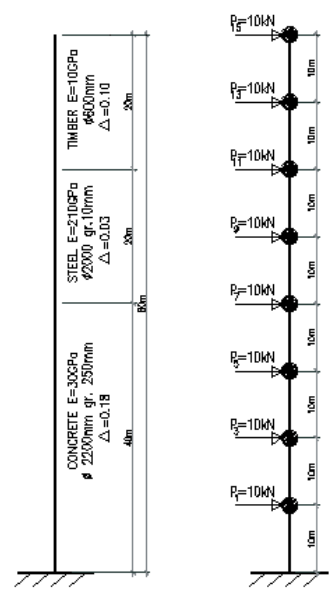

Fig. 2. Scheme of the structure.
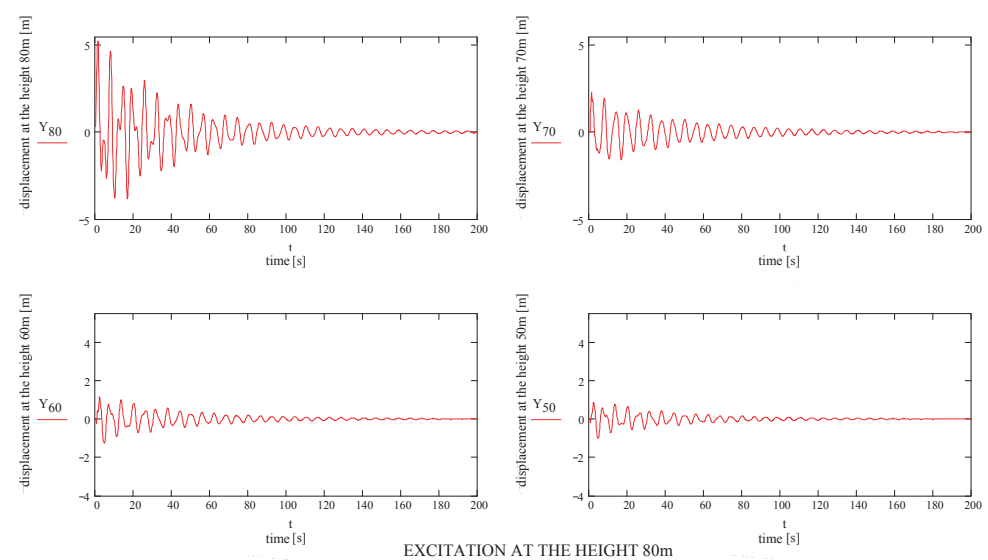

Fig. 3. Time history series (excitaion at $80 \mathrm{~m}$ ). 

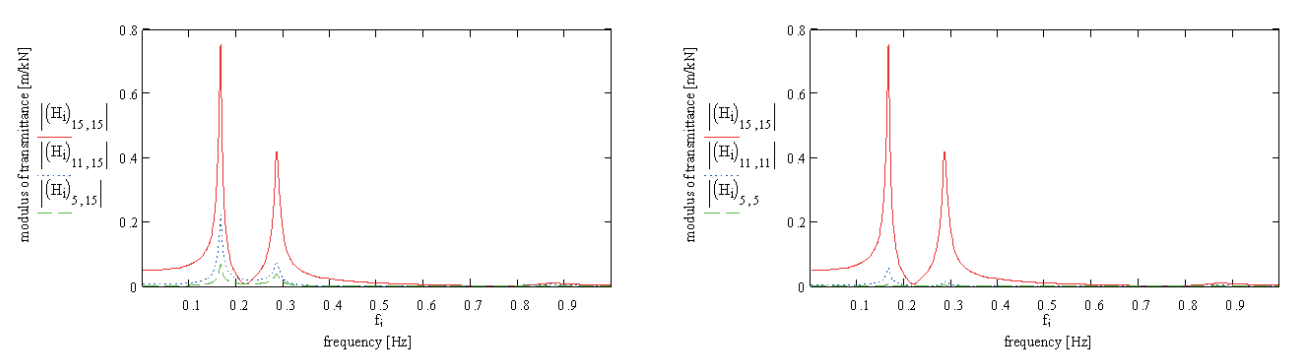

Fig. 4. Modulus of mechanical transmittance.

Table 1. Damping coefficient values $\delta$ obtained with use of collocation method and half power bandwith method.

\begin{tabular}{|c|c|c|c|c|c|c|c|}
\hline High & DOF & \multirow{2}{*}{ Eigenvalue } & \multirow[b]{2}{*}{$\delta$} & \multirow{2}{*}{ Eigenvalue } & \multirow{2}{*}{$\delta$} & \multirow{2}{*}{ Eigenvalue } & \multirow{2}{*}{$\delta$} \\
\hline$[\mathrm{m}]$ & Excitation/response & & & & & & \\
\hline 70 & $13 / 13$ & \multirow{8}{*}{$0.16 \mathrm{~Hz}$} & 0.126 & \multirow{8}{*}{$0.28 \mathrm{~Hz}$} & 0.098 & \multirow{8}{*}{$0.87 \mathrm{~Hz}$} & 0.249 \\
\hline 60 & $11 / 11$ & & 0.129 & & 0.113 & & 0.255 \\
\hline 50 & $9 / 9$ & & 0.129 & & 0.115 & & 0.229 \\
\hline 40 & $7 / 7$ & & 0.131 & & 0.118 & & - \\
\hline 70 & $15 / 13$ & & 0.133 & & 0.121 & & 0.213 \\
\hline 60 & $15 / 11$ & & 0.133 & & 0.121 & & 0.213 \\
\hline 50 & $15 / 9$ & & 0.134 & & 0.118 & & 0.261 \\
\hline 40 & $15 / 7$ & & 0.130 & & 0.118 & & 0.246 \\
\hline
\end{tabular}

Table 2. Damping coefficients values obtained with use of potential and kinetic energy method.

\begin{tabular}{ccccc}
\hline Energy & Eigenvalue & $\delta$ & Eigenvalue & $\delta$ \\
\hline Potencial Energy & $0.16 \mathrm{~Hz}$ & 0.126 & $0.28 \mathrm{~Hz}$ & 0.098 \\
Potencial Energy & & 0.129 & & 0.113 \\
\hline
\end{tabular}

\subsection{Model investigation - complex cantilever model}

Investigations of vibrations of models have been carried out by usage of HBM equipment: accelerometers B200, analyzer Spider 8 and steering program Catman 4.0. Experiments have been performed on cantilever models. Bending and torsional vibrations had been excited. Vibrations had been excited by bending or torsion and sudden release of the end of the model.

Two series of measurement have been performed:

- First series (complex model, I120, a pine board $80 \mathrm{~mm}$ x $48 \mathrm{~mm}$, length. $1.72 \mathrm{~m}$ - (Fig. 5)) accelerometers had been fixed in the middle, in the $3 / 4$ and at the end of the model.

- Second series (complex model, a flat $80 \mathrm{~mm} \times 8 \mathrm{~mm}$, pine board $120 \mathrm{~mm} \times$ $25 \mathrm{~mm}$, length-1.12m (Fig. 6)) accelerometers had been fixed in the $1 / 3$, the $2 / 3$ and at the end of the model.

Series of accelerations in time are the results of the measurements. It has been sampled with the frequency from $100 \mathrm{~Hz}$ to $3200 \mathrm{~Hz}$ for every model. On the basis of time processes, spectral analysis of vibrations have been performed by Catman program 4.0 (FFT). Natural circular frequencies obtained from investigation have been verified by performing calculations with use Algor program (FEM program), which confirmed the outcomes of investigation. 


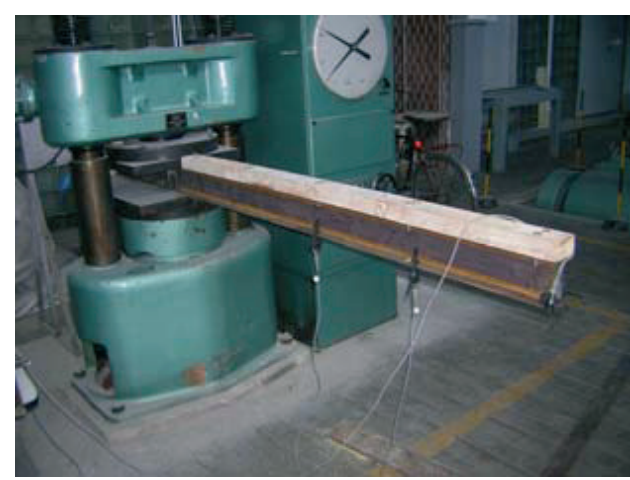

Fig. 5. Model 1.

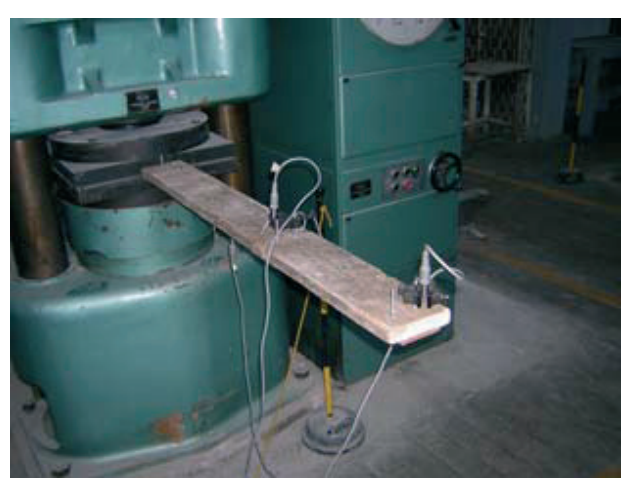

Fig. 6. Model 2.

Two methods have been used: the energetic method and the collocation method for determination of damping coefficient of vibrations in correspondence to modes of free vibrations. Both of them have been applied to real processes and obtained by mechanic transmittance. Matrices of stiffness of model, diagonal matrices of masses and modes of this model have been used for calculations. Damping coefficient values have been obtained on the basis of literature $[5,6,7]$. The values $\delta_{s}=0,05$ for steel and $\delta_{d}=0,1$ for wood have been assumed.

The comparison of obtained values $\delta$ is depicted in Tab. 3 and Tab. 4.

Table 3. Damping coefficients values $\delta$ - model 1.

\begin{tabular}{cccccc}
\hline Eigenvalue & $\begin{array}{c}\text { Number and modes of } \\
\text { free vibrations }\end{array}$ & $\begin{array}{c}\text { Potencial } \\
\text { Energy }\end{array}$ & $\begin{array}{c}\text { Kinetic } \\
\text { Energy }\end{array}$ & $\begin{array}{c}\text { Collocation } \\
\text { method } \\
\text { (investigation) }\end{array}$ & $\begin{array}{c}\text { Collocation } \\
\text { method } \\
\text { (FEM) }\end{array}$ \\
\hline$[\mathrm{Hz}]$ & & & & $\delta$ & \\
\hline 5.09 & 1 bending - horizontal & 0.067 & 0.052 & - & 0.037 \\
31.8 & 2 bending - horizontal & 0.067 & 0.052 & 0.050 & 0.042 \\
39.08 & 1 bending - vertical & 0.044 & 0.067 & 0.060 & 0.038 \\
\hline
\end{tabular}

Table 4. Damping coefficients values $\delta$ - model 2.

\begin{tabular}{cccccc}
\hline Eigenvalue & $\begin{array}{c}\text { Number and modes of } \\
\text { free vibrations }\end{array}$ & $\begin{array}{c}\text { Potencial } \\
\text { Energy }\end{array}$ & $\begin{array}{c}\text { Kinetic } \\
\text { Energy }\end{array}$ & $\begin{array}{c}\text { Collocation } \\
\text { method } \\
\text { (investigation) }\end{array}$ & $\begin{array}{c}\text { Collocation } \\
\text { method } \\
\text { (FEM) }\end{array}$ \\
\hline$[\mathrm{Hz}]$ & & & & $\delta$ & \\
\hline 7.3 & 1 bending - vertical & 0.080 & 0.068 & 0.130 & 0.048 \\
43.5 & 2 bending - vertical & 0.080 & 0.070 & - & 0.046 \\
\hline
\end{tabular}

\section{Conclusions}

The investigation of dynamic structure properties with the aid of Fourier transform allows examination of transmittances changes (and what follows also the responses of a building) depending on the changes in damping parameters of particular fragments of structure.

For the analyzed model, fixing mass-stiffness damping at the same parameters as for the first frequencies of proper vibrations, leads to overestimated damping parameters for higher frequencies (modified mass-stiffness damping model will be developed in the following stage of research). 


\section{References}

[1] Flaga A., Kawecki J., Kucwaj J., Zastosowanie charakterystyk częstotliwościowych do opisu własności dynamicznych obiektów budowlanych, Archiwum Inżynierii Lądowej - tom XXV z.4, 1979.

[2] Flaga A., Kawecki J., Twierdzenie o wzajemności transmitancji i wzajemności odpowiedzi impulsowych, Archiwum Inżynierii Lądowej - tom XXV z.1, 1979.

[3] Flaga A., Michałowski T., Charakterystyki tłumienia drgań lekkich kładek wiszacych $i$ podwieszonych, Inżynieria i Budownictwo nr 9 (2000) 495-497.

[4] Flaga A., Szulej J., Metoda wyznaczania wspótczynników ttumienia drgań konstrukcji zespolonych, Konferencja naukowa, Krynica wrzesień 2005, pp.: 49-54.

[5] Flaga A., Praktyczne ujęcie ttumienia drgań budowli jako całości, Zeszyt Naukowy Politechniki Krakowskiej, nr 6, 1979.

[6] Dyląg Z., Wytrzymałość materiałów, t. 2, WNT, Warszawa, 1997.

[7] Rakowski G., Mechanika budowli: ujęcie komputerowe, t. 2, Arkady, Warszawa, 1992.

[8] Yamaguchi H., Ito M., Mode-dependency of structural damping in cable-stayed bridges, $9^{\text {th }}$ ICWE, New Delhi, India, 1995, pp.: 928-937.

[9] Bachmann H., Vibration problems in structures, Wien, Bulletin D'Information, No 209, 1991. 